\title{
Trochanteric Bursa Is a Source of Connective Tissue Progenitor Cells
}

\author{
Matthew R. LeVasseur, M.D., Benjamin C. Hawthorne, B.S., Michael R. Mancini, B.S., \\ Mary Beth R. McCarthy, B.S., Ian J. Wellington, M.D., Mark P. Cote, D.P.T., M.S.C.T.R., \\ Olga Solovyova, M.D., Vincent J. Williams, M.D., and Augustus D. Mazzocca, M.S., M.D.
}

\begin{abstract}
Purpose: To investigate the presence of connective tissue progenitor cells (CTPs) in the trochanteric bursa harvested over the gluteus medius muscle belly and tendon during open hip procedures. Methods: Trochanteric bursa samples from nine patients $(63.1 \pm 8.6$ years) undergoing total hip arthroplasty for primary osteoarthritis were obtained from 2 sites: over the gluteus medius tendon at the greater trochanter and over the muscle belly. Bursal tissue was digested with collagenase and grown in culture. The nucleated cell count, cellular concentration, cellular proliferation, fluorescenceactivated cell sorting (FACS) analysis, and differentiation using immunostaining and quantitative polymerase chain reaction (PCR) were used to determine and quantify the presence of CTPs. Results: Bursa-derived CTPs were identified in all harvested samples. At $t=0$, there was no difference in nucleated cell count over muscle and tendon $\left(1.69 \pm 1.26 \times 10^{8}\right.$ and $1.41 \pm 1.12 \times 10^{8}$ cells/g, respectively; $P=.162$ ). Similarly, the cellular concentration at 3 weeks was not significantly different between bursa harvested over muscle and tendon $\left(6.61 \pm 5.14 \times 10^{6}\right.$ and $5.58 \pm 4.70 \times 10^{6}$ cells/g, respectively; $P=.532)$. High cellular proliferation was identified for both bursal tissue overlying muscle and tendon $(2.28 \pm .95$ and $1.66 \pm 1.05$, respectively; $P=.194)$. FACS analysis revealed high positivity rates $(>95 \%)$ of CTP-specific surface epitopes (CD105, CD90, and CD73) and low positivity rates $(<1.3 \%)$ of negative markers (CD45, CD31). Osteogenic, adipogenic, and chondrogenic differentiation potential was demonstrated with immunostaining and quantitative PCR for gene expression. Conclusions: Connective tissue progenitor cells are found in the trochanteric bursa overlying the muscle and tendon of the hip abductors. Clinical Relevance: During open hip procedures, the trochanteric bursa is often partially excised to identify muscular boundaries and tissue planes for surgical exposure. The function of the trochanteric bursa remains largely unknown. However, this tissue is a source of connective tissue progenitor cells, which may be important in the healing response of surgically repaired abductor tendons.
\end{abstract}

\section{Introduction}

B ursal tissue has been identified as a robust source of connective tissue progenitor cells (CTPs)..$^{1-3}$ In recent investigations, the increased interest in bursal tissue has emerged for its potential role in augmenting tendon repairs, particularly in rotator cuff tendons. ${ }^{4-7}$ However, it is unknown whether bursal tissue from

From the Department of Orthopaedic Surgery, University of Connecticut, Farmington, Connecticut, U.S.A.

The authors report the following potential conflicts of interest or sources of funding: M.P.C. reports personal fees from Arthroscopy Association of North America, outside the submitted work. A.D.M. reports research grants from Arthrex, and is a consultant for Arthrex. Full ICMJE author disclosure forms are available for this article online, as supplementary material.

Received March 11, 2021; accepted July 25, 2021.

Address correspondence to Matthew R. LeVasseur, M.D., 263 Farmington Ave.,Farmington, CT 06030,U.S.A. E-mail: mlevasseur@uchc.edu

(C) 2021 THE AUTHORS. Published by Elsevier Inc. on behalf of the Arthroscopy Association of North America. This is an open access article under the CC BY-NC-ND license (http://creativecommons.org/licenses/by-nc-nd/4.0/). 2666-061X/21349

https://doi.org/10.1016/j.asmr.2021.07.022 different sites of the human body contains CTPs, alternatively known as mesenchymal stem cells (MSCs). Similar to the subacromial bursa, the trochanteric bursa is commonly excised during total hip arthroplasty (THA) to assist with defining anatomic landmarks for the surgical approach. Studies have implicated bursal tissue in the healing response of injured tendons. ${ }^{8-11}$ In particular, subacromial bursal tissue has been shown to manifest hypertrophy, hyperplasia, and neoangiogenesis, which suggest a role in the reparative response. ${ }^{8,9}$ However, the specific biologic role of bursal tissue and its mechanism, and perhaps more importantly, the magnitude of its effect, on tendon healing is unknown. Moreover, differences in cellular proliferation have been identified from subacromial bursa overlying tendon versus muscle. ${ }^{2}$ Elsewhere, the cells of the paratenon enveloping the patellar tendon in rodents have been observed to change cellular expression as a consequence of trauma to promote healing. ${ }^{12}$ To further understand the biological role of bursal tissue overlying muscle attachment sites, additional entheses need to be analyzed. 
The purpose of the study was to investigate the presence of connective tissue progenitor cells (CTPs) in the trochanteric bursa harvested over the gluteus medius muscle belly and tendon during open hip procedures. We hypothesized that the trochanteric bursa would be a robust source of connective tissue progenitor cells, and there would be no difference in the cellular viability and differentiation potential of cells taken from the bursa overlying the tendon and muscle belly.

\section{Methods}

Prior to initiation of the study, institutional review board (IRB) approval was granted. This investigation was performed at the Department of Orthopaedic Surgery, University of Connecticut, Farmington, Connecticut. Specimens were obtained from nonconsecutive patients undergoing primary total hip arthroplasty by one of two fellowship-trained arthroplasty surgeons between June 2020 and August 2020. Inclusion criteria included patients older than 18 years of age undergoing primary, unilateral total hip arthroplasty for primary degenerative osteoarthritis. Patients were excluded if they had a history of avascular necrosis, septic arthritis, inflammatory arthropathy, rheumatologic conditions (e.g., rheumatoid arthritis, gout, and pseudogout), trochanteric bursitis or bursal injection (e.g., corticosteroid, local anesthetic, platelet-rich plasma, and stem cells), hip abductor injury or tear, or ipsilateral hip surgery. Patients of vulnerable patient populations were also excluded such as prisoners and pregnant women. Smokers (current or former) were not excluded as a previous study of subacromial bursaderived CTPs found that smoking status did not affect cellular proliferation or cell density. ${ }^{3}$ Additionally, all current smokers were required to abstain from smoking for at least 3 months prior to surgery under the direction of the surgeon. Demographic information, including age, sex, and medical comorbidities were obtained for each patient. Ethical approval was obtained via Human Research Determination Form to the IRB of the University of Connecticut (IRB \# IE-07-224-2).

\section{Specimen Collection}

Using a direct lateral approach to the hip in the lateral decubitus position, we identified the hip abductors and overlying bursa after incision and retraction of the iliotibial band and tensor fascia lata. Using electrocautery, we excised the bursa overlying the hip abductor tendon at the insertion to the greater trochanter and bursa overlying the gluteus medius musculature was excised and collected in 2 separate sterile specimen cups filled with saline (Fig 1). Harvesting was completed once approximately 2 grams of tissue was obtained for each sample. The specimens were then immediately transported to the research laboratory and stored overnight in a $4^{\circ} \mathrm{C}$ refrigerator. Secondary to the long-time commitment and requirement for ancillary staff to perform fluorescence-activated cell sorting (FACS) analysis, processing was delayed until the next day. All specimens were processed within 24 hours of collection.

\section{Digestion and Nucleated Cell Count}

First, the tissue was gently blotted to remove excess fluid on the samples. A scalpel was used to remove sections of cauterized bursal tissue prior to processing. Then, the mass of the bursa samples collected over the tendon and muscle was recorded. For all experiments, bursal tissue overlying the hip abductor tendon and overlying the muscle were processed separately. A small portion of the tissue was isolated and minced with tenotomy scissors for 2 minutes to aid in tissue digestion. This tissue was transferred to a 50-mL screw cap conical centrifuge tube containing $30 \mathrm{~mL}$ of Dulbecco's modified Eagle's medium (DMEM) $(1 \times$; Thermo Fisher Scientific, Waltham MA) and $2 \mathrm{mg} / \mathrm{mL}$ of sterile Collagenase P (Sigma-Aldrich, St. Louis, MO). For tissue digestion, the tubes were secured on a rocking platform and placed in a humidified $37^{\circ} \mathrm{C}$ incubator maintained at $5 \% \mathrm{CO}_{2}$ concentration for 2 hours or until the tissue was visibly digested. To achieve a singular cell suspension, the digested samples were passed through a 70- $\mu \mathrm{m}$ nylon mesh cell strainer (Fisher Scientific, Pittsburgh, PA). The number of cells (cells $/ \mathrm{mL}$ ) was calculated using a $\mathrm{Zl}$ Coulter Particle Counter (Beckman Coulter Life Sciences, Indianapolis, IN), calibrated to detect particles $>8 \mu \mathrm{m}$, after adding $500 \mu \mathrm{L}$ of the cellular solution to a transparent cuvette containing $9.5 \mathrm{~mL}$ of $0.9 \% \mathrm{NaCl}$ solution. The nucleated cell count was then calculated by multiplying the number of cells per unit volume by the total volume of solute $(30 \mathrm{~mL})$. The nucleated cell count per mass (cells/g) was calculated by normalizing with respect to the total mass of the digested tissue.

\section{Cell Culture}

Using a previously described technique to culture bursal cells ${ }^{4}$, the tissue was minced with tenotomy scissors and plated in complete culture medium containing DMEM, 10\% fetal bovine serum (FBS) (Thermo Fisher Scientific), and .1\% penicillin/streptomycin (Thermo Fisher Scientific) in two different arrangements: two Corning Primaria 100-mm dishes (Thermo Fisher Scientific) and eight wells of a Falcon Primaria 24-well plate (Becton Dickinson and Company, Franklin Lakes, NJ). The $100-\mathrm{mm}$ dishes were plated with $200 \mathrm{mg}$ of tissue with $10 \mathrm{~mL}$ of complete medium and were later used for differentiation and FACS analysis at confluence. The 24 -well plates were plated with $50 \mathrm{mg}$ of tissue with $1 \mathrm{~mL}$ of complete medium and were later used for measuring cellular concentration and proliferation at 3 weeks. Cells were grown at $37^{\circ} \mathrm{C}$ in a $5 \%$ humidified $\mathrm{CO}_{2}$ incubator. ${ }^{1,13}$ Complete DMEM medium was changed twice weekly. 


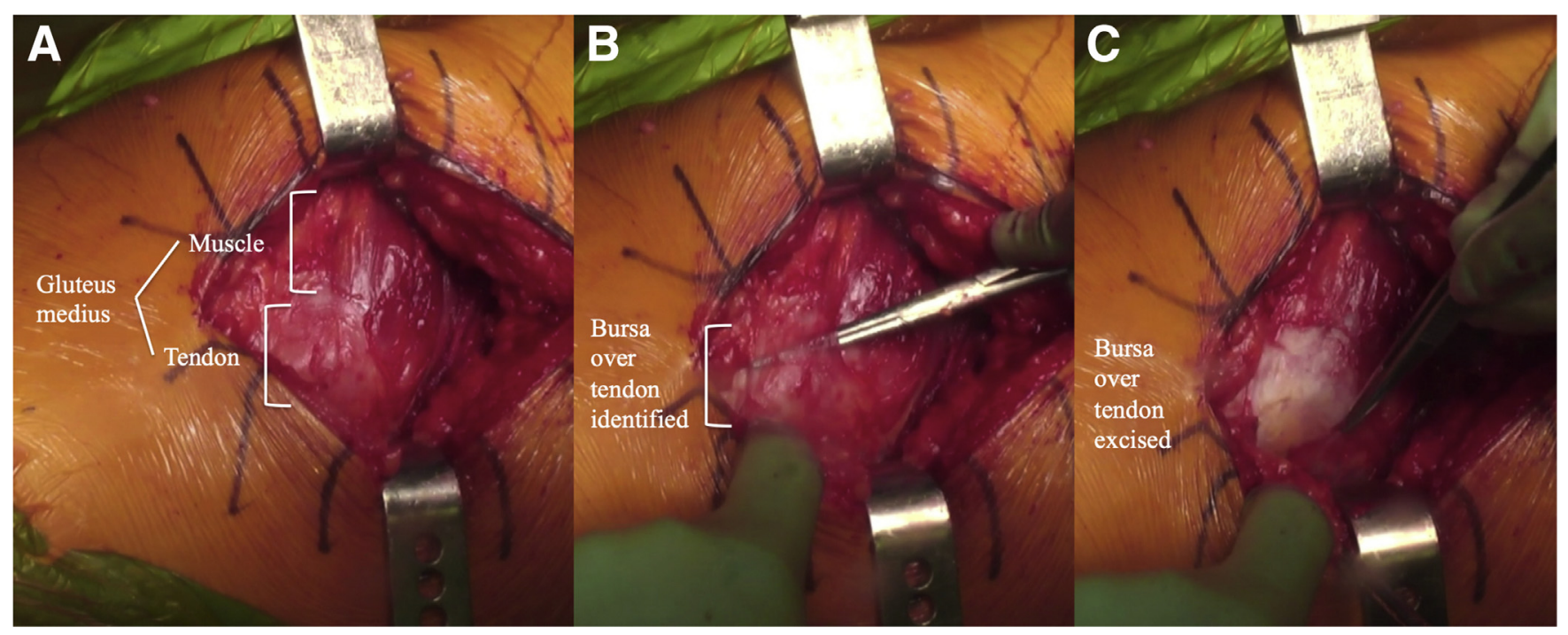

Fig 1. Intraoperative harvesting of the trochanteric bursa from a left hip. Following retraction of the iliotibial band and tensor fascia lata, the trochanteric bursa can be identified overlying the gluteus medius. (A) Bursal tissue was retrieved from 2 sites: overlying the tendon and overlying the muscle. (B, C) Trochanteric bursa overlying the gluteus medius tendon was identified and excised, revealing the white appearance of the underlying tendon.

\section{Cellular Concentration}

Following 3 weeks in culture, the four wells of the 24well plate designated for cellular concentration were trypsinized using sterile $0.5 \%$ trypsin/ethylenediaminetetraacetic acid (EDTA) to release the cells from the tissue culture plastic. Similar to the nucleated cell count at $t=0,500 \mu \mathrm{L}$ of the cellular suspension was added to a transparent cuvette containing $9.5 \mathrm{~mL}$ of $0.9 \% \mathrm{NaCl}$ solution and the number of cells that migrated out of the tissue and divided were counted using the Zl Coulter Counter. The cellular concentration (cells/g) was calculated by normalizing with respect to the total mass of plated tissue.

\section{Cellular Proliferation}

Following 3 weeks in culture, cellular viability and their ability to proliferate were determined using the XTT (2,3-bis (2-methoxy-4-nitro-5-sulfophenyl)-5[(phenylamino) carbonyl]-2H-tetrazolium hydroxide) assay (Roche Diagnostics, Mannheim, Germany). ${ }^{2}$ This test uses an ELISA reader to measure the absorbance of a soluble, brightly colored formazan salt that is created as an end product of an electron-coupling reaction that only occurs in the mitochondria of viable cells. Using 96-well plates (Corning, Corning, NY), cultures were incubated in XTT labeling mixture for 24 hours. The absorbance at $450 \mathrm{~nm}$ with a reference wavelength of $650 \mathrm{~nm}$ was measured using an automated plate reader (BioTek, Bad Friedrichshall, Germany). ${ }^{2,14}$

\section{FACS Analysis}

Fluorescence-activated cell sorting (FACS) analysis was completed at cell culture confluence, approximately 3 weeks after plating. On the basis of the consensus of the International Society for Cellular Therapy, cells expressing the surface epitopes CD105, CD90, and CD73 and lacking CD45 and CD31 are required criteria to be labeled mesenchymal stem cells. ${ }^{15}$ FACS analysis uses fluorescent antibodies to target these surface markers and quantifies their presence using an emission profile. Culture plates were trypsinized to lift the cells, spun into a pellet, and $10^{6}$ cells were resuspended in $100 \mu \mathrm{L}$ of staining buffer $(1 \times$ phosphate-buffered saline [PBS] with $10 \%$ fetal bovine serum [FBS] [Thermo Fisher Scientific] and 1\% human serum) containing a fluorescein isothiocyanate (FITC) or phycoerythrin (PE) antibody. All antibodies were obtained from BD Biosciences (San Diego, CA). Testing was completed using a BD LSR II flow cytometer (BD Biosciences) and analyzed using BD FACSDiva software (BD Biosciences).

\section{Differentiation, Immunostaining, and Quantitative PCR}

Following confluence of cells in culture, cells were split and three different medias were created to allow osteogenic, chondrogenic, and adipogenic differentiation, as well as cell culture plates designated to serve as controls. Cell culture medium was changed twice weekly for 21 days, to allow confluence of cells. Cell lines were stained and quantitative polymerase chain reaction (PCR) was used to measure the gene expression among the 3 different cell lines (osteogenic, adipogenic, and chondrogenic cells). ${ }^{2}$ First, the RNA was isolated using TRIzol reagent (Invitrogen Thermo Fisher Scientific, Carlsbad, CA). Using a Nanodrop (Thermo Scientific, Wilmington, DE), we quantified the purity of the RNA sample. Next, the RNA was reverse transcribed 
into complementary DNA using $1 \mathrm{mg}$ messenger RNA and a High Capacity Reverse Transcription Kit (Invitrogen). Quantitative PCR was performed using 8 ng complementary DNA as a template, in triplicate, and the StepOne Real-Time PCR system (Applied BioSystems, Foster City, CA). ${ }^{2}$ Expression of glyceraldehyde-3-phosphate dehydrogenase (Hs99999905_ml) was used as a control.

\section{Osteogenic Differentiation}

Cells were plated at a density of $3.0 \times 10^{4} \mathrm{cells} / \mathrm{cm}^{2}$ on $100-\mathrm{mm}$ dishes. ${ }^{16}$ The osteogenic differentiation media contained DMEM, 10\% FBS, 1 nM dexamethasone, $20 \mathrm{mM} \beta$-glycerophosphate, and $50 \mu \mathrm{g} / \mathrm{mL}$ ascorbate-2 phosphate. ${ }^{17}$ Control media were complete DMEM. Following fixation in $100 \%$ methanol, cells were stained with alizarin red to identify mineralized bone nodule formation. ${ }^{18}$ Gene expression of osteogenic samples was evaluated by measuring alkaline phosphatase (ALP; Hs01029144_ml) and collagen type I alpha 1 (COLlAl; Hs00164004_ml). ${ }^{19}$

\section{Adipogenic Differentiation}

Cells were plated at a density of $6.0 \times 10^{4} \mathrm{cells} / \mathrm{cm}^{2}$ on 100-mm dishes. ${ }^{16}$ The adipogenic differentiation media contained DMEM, 10\% FBS, $100 \mathrm{nM}$ dexamethasone, $\quad 0.5 \mathrm{mM}$ isobutyl-L-methylxanthine (Sigma-Aldrich), and $50 \mu \mathrm{M}$ indomethacin (SigmaAldrich). ${ }^{20}$ Control media used was complete DMEM. Following fixation in $70 \%$ ethanol, cells were stained with Oil Red-O solution. ${ }^{18}$ Adipogenic samples were evaluated by measuring fatty acid binding protein 4 (FAB4; Hs01086177_ml) and peroxisome proliferatoractivated receptor $\gamma$ (PPAR- $\gamma$; Hs01115513_ml). ${ }^{11}$

\section{Chondrogenic Differentiation}

Chondrogenic differentiation followed the protocol of Hatakeyama et al., which required the use of a cellular pellet. ${ }^{21}$ Cells at a density of $5.0 \times 10^{5}$ cells $/ \mathrm{mL}$ were added to 15-mL polypropylene tubes (Falcon; BD, Franklin Lakes, NJ) and centrifuged at $450 \mathrm{~g}$ for 10 minutes. ${ }^{16}$ The supernatant was discarded, leaving the cellular pellet. Chondrogenic differentiation media contained high-glucose DMEM, $10 \mathrm{ng} / \mathrm{mL}$ transforming growth factor- $\beta-1$ (TGF- $\beta-1$, R\&D Systems, Minneapolis, MN), $100 \mathrm{nM}$ dexamethasone (Sigma-Aldrich), 50 $\mu \mathrm{g} / \mathrm{mL}$ ascorbate-2-phosphate (Sigma-Aldrich), $40 \mu \mathrm{g} /$ $\mathrm{mL}$ proline (Sigma-Aldrich), $100 \mu \mathrm{g} / \mathrm{mL}$ pyruvate (Sigma-Aldrich), and $50 \mathrm{mg} / \mathrm{mL}$ liquid media supplement (ITS +1; Sigma-Aldrich; containing bovine insulin, human transferrin, sodium selenite, bovine serum albumin, and linoleic acid). Control media were similar, except TGF- $\beta$ - 1 was not added. During medium changes, it was important to not aspirate the pellet following centrifuging of the sample. For microscopic analysis, pellets were dehydrated in a series of alcohols, embedded in paraffin, cut into $5-\mu \mathrm{m}$ sections, and stained with Alcian Blue and type II collagen. Chondrogenic gene expression was evaluated by measuring collagen type II alpha 1 (COL2Al; Hs00264051_ml) and sex-determining region Y-box 9 (SOX9; Hs00165814_ml). ${ }^{22}$

\section{Statistical Analysis}

For statistical analysis, continuous variables were presented as means and standard deviations (SD), and categorical variables were summarized using frequencies and proportions. The paired $t$-test was used to compare means in cell density (cells/mg), proliferation, gene expression, and surface epitopes from hip abductor bursa taken from over the muscle and tendon where appropriate. A $P$ value of $<0.05$ was considered statistically significant. All statistical analyses were performed with Stata Statistical Software (StataCorp, College Station, TX)

\section{Results}

In the study period, 22 patients underwent primary total hip arthroplasty. Nine patients were excluded because of unavailability of laboratory personnel, two patients were excluded because of a diagnosis of avascular necrosis, one patient because of a history of inflammatory arthropathy, and one prisoner. This resulted in in a final study population of nine patients. The cohort consisted of seven females and two males with an average patient age of $63.1 \pm 8.6$ years (range, 54 to 82 ). The average sample of trochanteric bursa harvested over the gluteus medius muscle was $2.18 \pm 1.60 \mathrm{~g}$ and over the gluteus medius tendon was $1.52 \pm 0.82 \mathrm{~g}$. Patient demographics are shown in Table 1.

\section{Nucleated Cell Count}

There was no difference in nucleated cell count per mass between bursa over the gluteus medius muscle (1.69 \pm $1.26 \times 10^{8}$ cells $/ g$; range, $9.69 \times 10^{6}$ to $4.27 \times 10^{8}$ cells $/ g$ ) and over the tendon $\left(1.41 \pm 1.12 \times 10^{8}\right.$ cells $/ g$, range, $1.31 \times 10^{7}$ to $3.41 \times 10^{8}$ cells $\left./ g\right)(P=.162)$.

\section{Cellular Concentration}

Following 3 weeks in culture, trochanteric bursa samples demonstrated high cellular concentrations with no significant differences between those derived from overlying muscle $\left(6.61 \pm 5.14 \times 10^{6}\right.$ cells/g; range, $1.53 \times 10^{6}$ to $1.85 \times 10^{7}$ cells $\left./ g\right)$ or tendon $(5.58 \pm 4.70 \times$ $10^{6}$ cells/g; range, $2.45 \times 10^{5}$ to $1.38 \times 10^{7}$ cells/g) $(P=.532)$. Cellular concentrations are shown in Fig 2 .

\section{Cellular Proliferation}

Following 3 weeks in culture, both trochanteric bursa samples demonstrated high cellular proliferation using the XTT assay. The mean cellular proliferation index for the trochanteric bursa overlying the gluteus medius 
Table 1. Patient Demographic Data

\begin{tabular}{|c|c|c|}
\hline Characteristic & Means \pm SD & Range \\
\hline Age, yr & $63.1 \pm 8.6$ & $54-82$ \\
\hline \multirow[t]{2}{*}{ BMI, $\mathrm{kg} / \mathrm{m}^{2}$} & $32.6 \pm 6.8$ & $20.1-40.7$ \\
\hline & $n$ & $\%$ \\
\hline \multicolumn{3}{|l|}{ Sex } \\
\hline Female & 7 & $78 \%$ \\
\hline Male & 2 & $22 \%$ \\
\hline \multicolumn{3}{|l|}{ Laterality } \\
\hline Left & 6 & $67 \%$ \\
\hline Right & 3 & $33 \%$ \\
\hline \multicolumn{3}{|l|}{ Diabetes } \\
\hline Yes & 0 & $0 \%$ \\
\hline No & 9 & $100 \%$ \\
\hline \multicolumn{3}{|l|}{ Smoker } \\
\hline Current & 3 & $33 \%$ \\
\hline Former & 3 & $33 \%$ \\
\hline Never & 3 & $33 \%$ \\
\hline \multicolumn{3}{|l|}{ Alcohol } \\
\hline Yes & 2 & $22 \%$ \\
\hline No & 7 & $78 \%$ \\
\hline \multicolumn{3}{|c|}{$\begin{array}{l}\text { Prior intra-articular } \\
\text { corticosteroid injection }\end{array}$} \\
\hline Yes & 5 & $56 \%$ \\
\hline No & 4 & $44 \%$ \\
\hline
\end{tabular}

BMI, body mass index.

muscle was $2.28 \pm 0.95$ and overlying the tendon was $1.66 \pm 1.05$, with absorbance measured at $450 \mathrm{~nm}$ compared to the $650-\mathrm{nm}$ reference wavelength $(P=.194)$. These results are shown in Fig 3 .

\section{FACS Analysis}

Trochanteric bursal cells from tissue overlying both the gluteus medius muscle and tendon expressed high positivity (95 to $100 \%$ ) for mesenchymal stem cell markers (CD 105, CD90, and CD73) and low positivity (.58 to $1.3 \%$ ) for hematopoietic surface markers (CD45 and CD31), suggesting appropriate isolation of MSCs as defined by the International Society for Cellular Therapy. ${ }^{15}$ There was no difference in the positivity rates of all surface epitopes between bursa over the muscle and bursa over the tendon (Fig 4).

\section{Osteogenic Differentiation}

Osteogenic potential of connective tissue progenitor cells was determined through alizarin red staining and PCR to identify gene expression of alkaline phosphatase (ALP) and type I collagen alpha 1 (COLlAl) compared to patient-matched control samples. All cell colonies induced with the osteogenic differentiation media stained positively with alizarin red, contrary to controls (complete DMEM). Quantitative PCR identified similar mean gene expression ratios for bursa overlying muscle and tendon for both ALP (21.0 \pm 7.4 vs. $21.0 \pm 5.7 ; P=$ $.180)$ and COLlAl ( $3.0 \pm 2.8$ vs. $4.4 \pm 1.0 ; P=.180)$. Osteogenic differentiation results are shown in Fig 5.

\section{Adipogenic Differentiation}

Adipogenic potential of connective tissue progenitor cells was determined through Oil Red-O staining and PCR to identify gene expression of fatty acid binding protein 4 (FAB4) and peroxisome proliferatoractivated receptor $\gamma$ (PPAR- $\gamma$ ) compared to patientmatched control samples. All cell colonies induced with the adipogenic differentiation media stained positively with Oil Red-O. All controls (complete DMEM) failed to stain with Oil Red-O. Quantitative PCR identified similar mean gene expression ratios for PPAR- $\gamma$ for bursal tissue overlying gluteus medius muscle and tendon $(1.6 \pm .4$ vs. $1.5 \pm .1 ; P=.465)$. However, there was significantly greater gene expression of FAB4 over the muscle compared to tendon $(2.2 \pm 1.0$ vs. $1.3 \pm .4 ; P=.028)$. Adipogenic differentiation results are shown in Fig 6.

\section{Chondrogenic Differentiation}

Chondrogenic potential of connective tissue progenitor cells was determined through Alcian Blue and type II collagen staining, as well as PCR to identify gene expression of collagen type II alpha 1 (COL2Al) and sex-determining region Y-box 9 (SOX9) compared to patient-matched control samples. All cell colonies induced with the chondrogenic differentiation media stained positively for Alcian Blue and type II collagen, while controls (similar media without TGF- $\beta$ ) failed to stain. Quantitative PCR identified similar mean gene expression ratios for bursa overlying muscle and tendon for both COL2Al $(2.3 \pm 1.6$ vs. $4.6 \pm 3.1 ; P=.463)$ and SOX9 $(4.0 \pm 2.4$ vs. $2.9 \pm 2.7 ; P=.600)$. Chondrogenic differentiation results are shown in Fig 7 .

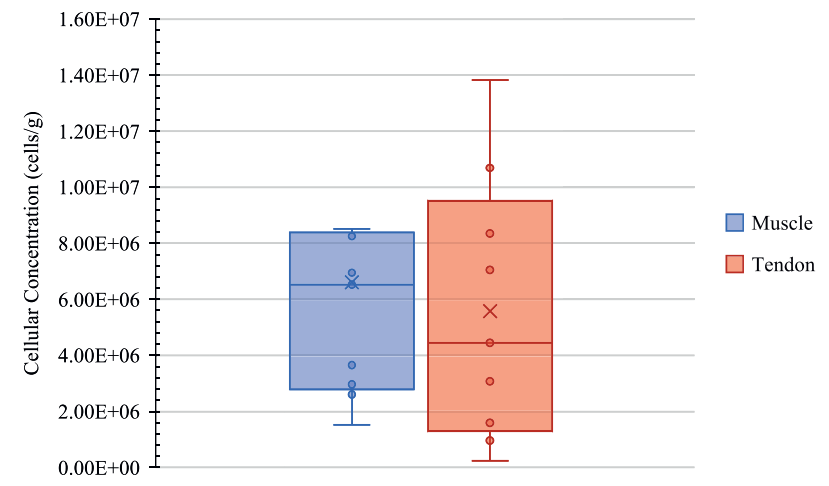

Fig 2. Cellular concentration of trochanteric bursa cells. Following 3 weeks in culture in complete Dulbecco's modified Eagle's medium (DMEM), high cellular concentrations (cells/ g) were identified from bursal tissue overlying the gluteus medius muscle and tendon with no significant differences $(P=.532)$. The values are represented as the mean (" $\mathrm{X}$ " marker), median (line), interquartile range (box), and range (whiskers). 


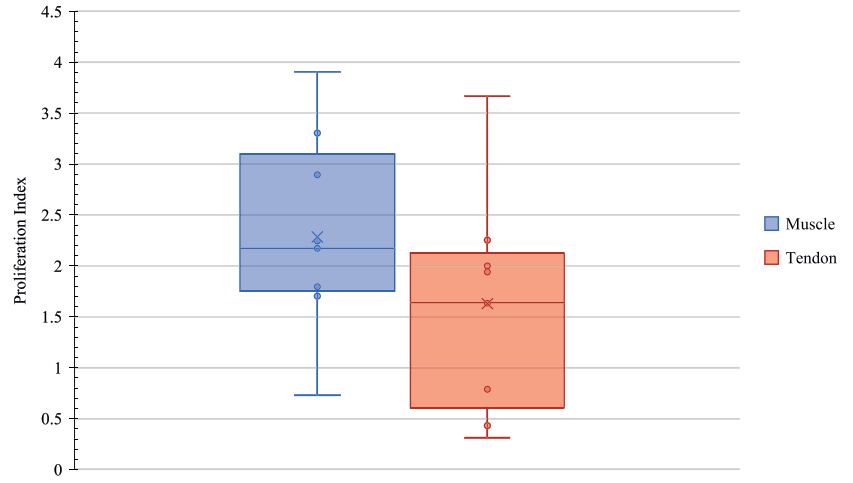

Fig 3. Cellular proliferation of trochanteric bursa cells. XTT analysis was used to assess the cellular proliferation rate by measuring the absorbance of formazan salt at $450 \mathrm{~nm}$ following 3 weeks in culture. Both trochanteric bursa samples demonstrated high rates of cellular proliferation with no significant differences between those derived from overlying the gluteus medius muscle and tendon $(P=.194)$. The values are represented as the mean (" $\mathrm{X}$ " marker), median (line), interquartile range (box), and range (whiskers). XTT, (2,3-bis (2-methoxy-4-nitro-5-sulfophenyl)-5[(phenylamino) carbonyl]-2H-tetrazolium hydroxide).

\section{Discussion}

The most important finding of this study was that bursal tissue overlying the hip abductors contains connective tissue progenitor cells. These cells showed similar in vitro behaviors as those derived from the subacromial bursa, with high cellular viability and proliferation, as well as excellent potentials for differentiation into osteogenic, adipogenic, and chondrogenic lineages..$^{2-4,23,24}$ We further observed no difference in the nucleated cell count, CTP cellular concentration, proliferation, and expression of CTPspecific surface markers in the bursal tissue collected over the tendon compared to over the muscle belly of the hip abductors. The biologic role of these cells is unknown but may parallel those of the subacromial bursa and the rotator cuff.

Hip abductor tears have been described as the rotator cuff tears of the hip. ${ }^{25,26}$ This pathology is more prevalent in older populations, causing pain, local tenderness, kinematic changes, and weakness. Furthermore, these tears may occur with or without a known traumatic event. Howell et al. hypothesized that these tears were secondary to ischemia of the vascular watershed at the intertrochanteric line with resultant degenerative changes, leading to tears. ${ }^{27}$ Similar to the rotator cuff, repair techniques include suture fixation, suture anchors, transosseous bone tunnels, muscle transfers (e.g., gluteus maximus), and allografts (e.g., Achilles, acellular dermal allografts), using either endoscopic or open approaches. Moreover, outcomes are worse when fatty atrophy is present. Importantly, preoperative degeneration of the hip abductors can be seen in $20 \%$ to $25 \%$ of THA patients, which has been linked as a strong contributor to postoperative abductor deficiency in addition to failed tenotomy repairs. ${ }^{27-29}$ Akin to the shoulder, repair results are inconsistent, and failures may be impeded by a biologic problem.

Bursal tissue has been implicated in the healing response of injured tendons. ${ }^{8-11}$ Multiple recent investigations have identified cells derived from the subacromial bursa to garnish osteogenic, adipogenic, and chondrogenic differentiation potentials. ${ }^{1,2,6,13,30}$ These potentials have been demonstrated with gene expression profiles using quantitative $\mathrm{PCR}^{2}$, flow cytometry for mesenchymal stem cell-specific surface markers ${ }^{3,4,13,23,24}$, and histological staining. ${ }^{2,13}$ Morikawa et al. quantified gene expression levels for proteins specific to osteogenic, adipogenic, and chondrogenic lineages for cells derived from the subacromial bursal tissue overlying the muscle and tendon

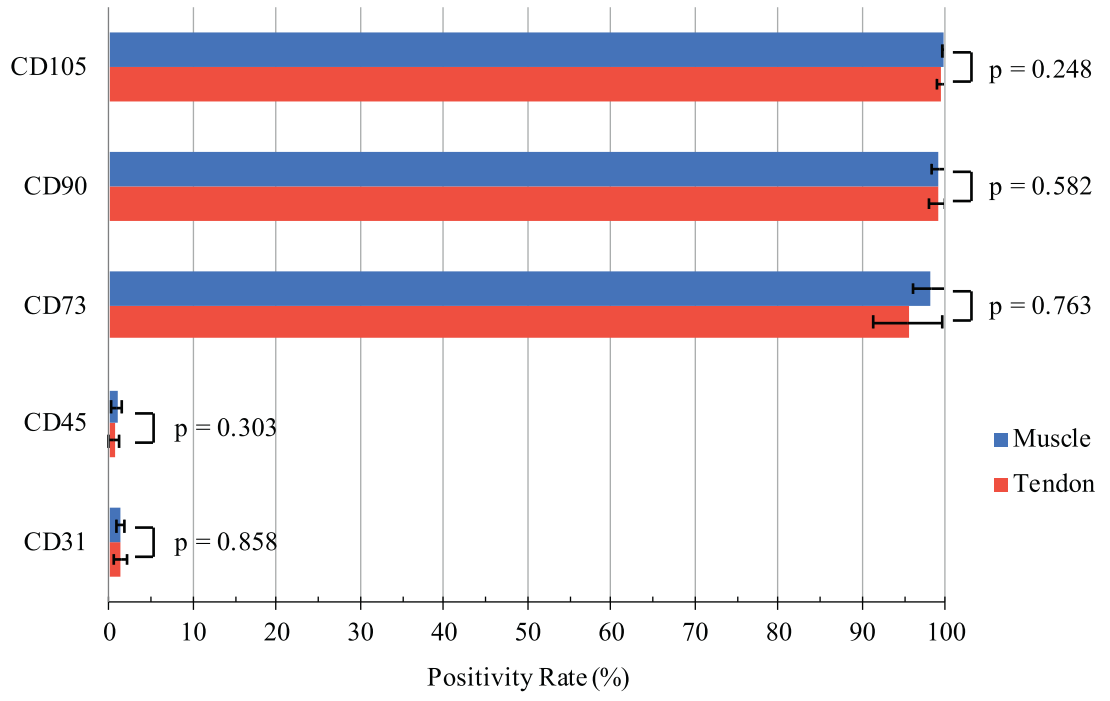

Fig 4. Positivity rates of CTP-specific surface markers using flow cytometry. Trochanteric bursa samples over the gluteus medius muscle and tendon demonstrated high positivity rates of CTP-specific surface markers including CD105, CD90, and CD73 and low positivity rates of negative markers including CD45 and CD 31. These findings are consistent with the criteria described by Dominici et al. ${ }^{15}$ The values are presented as the mean positivity rate $(\%)$ with standard deviation bars. CTP, connective tissue progenitor cell. 
Fig 5. Osteogenic differentiation immunostaining and quantitative PCR. Alizarin Red staining in controls (A) and those induced with osteogenic differentiation media (B) at $\times 10$ magnification. Trochanteric bursa overlying the gluteus medius muscle and tendon revealed similar gene expression ratios for ALP (C) $(P=.180)$ and COLlAl (D)
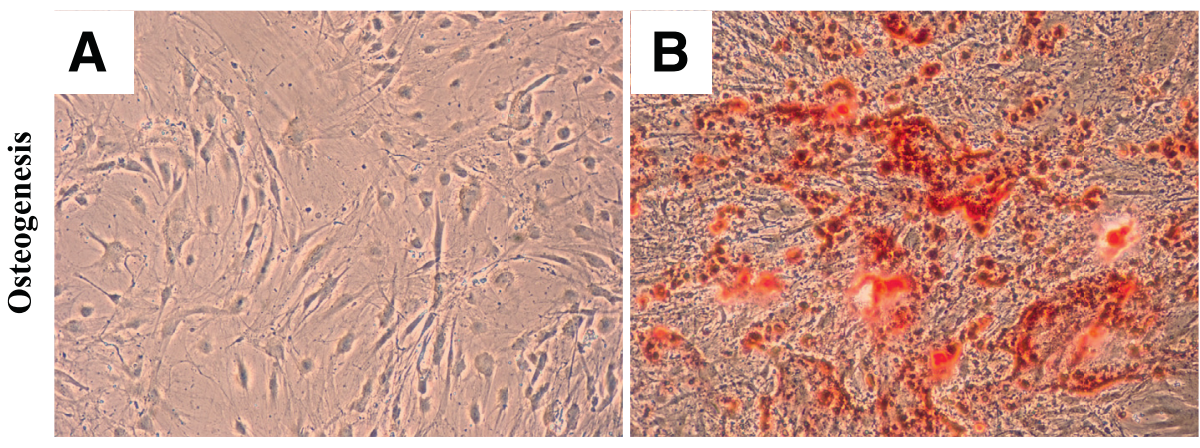

Alizarin Red

C

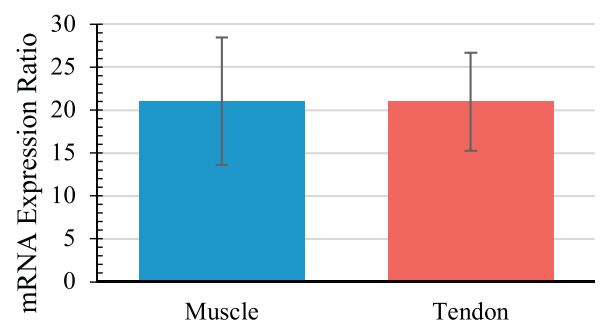

D

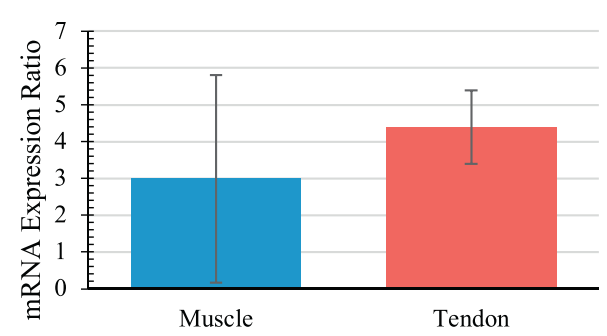

of the rotator cuff. ${ }^{2}$ These authors identified similar expression profiles for the two harvesting sites. Similarly, the current study identified similar gene expression ratios for the differentiated cells from the trochanteric bursa overlying the gluteus medius muscle belly and tendon, excluding fatty acid binding protein 4 (FAB4), which was found to be significantly greater in the bursal tissue over the muscle belly. Macroscopically,

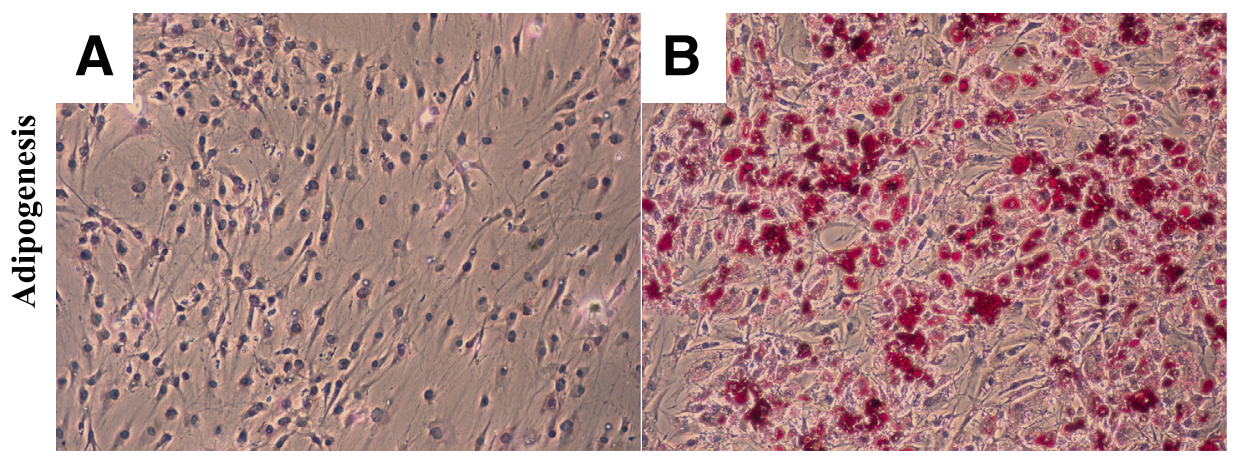

Oil Red-O
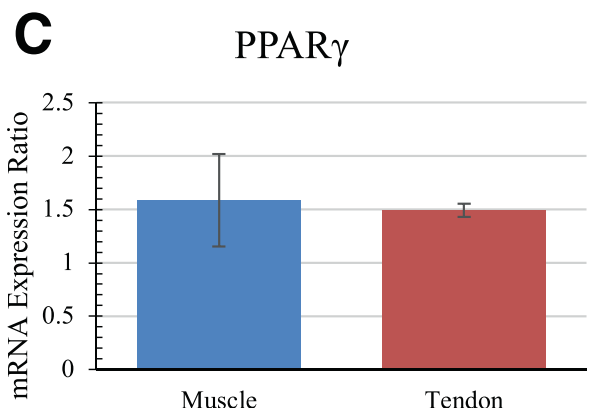

D

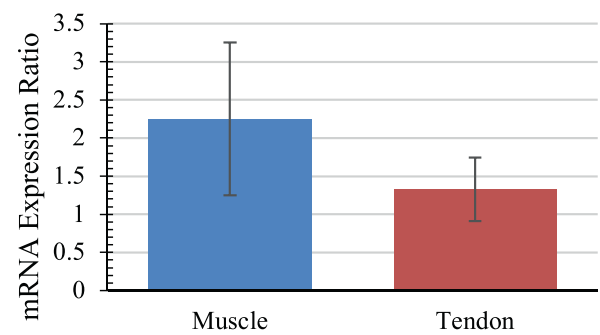

Fig 6. Adipogenic differentiation immunostaining and quantitative PCR. Oil Red-O staining in controls (A) and those induced with adipogenic differentiation media (B) at $\times 10$ magnification. Trochanteric bursa overlying the gluteus medius muscle and tendon revealed similar gene expression ratios for PPAR- $\gamma(C)(P=.465)$; however, bursa taken from over the muscle revealed significantly greater expression of FAB4 compared to bursa over the tendon (D) $(P=$ $.028)$. FAB4, fatty acid binding protein 4; PCR, polymerase chain reaction; PPAR- $\gamma$; peroxisome proliferator-activated receptor $\gamma$. 

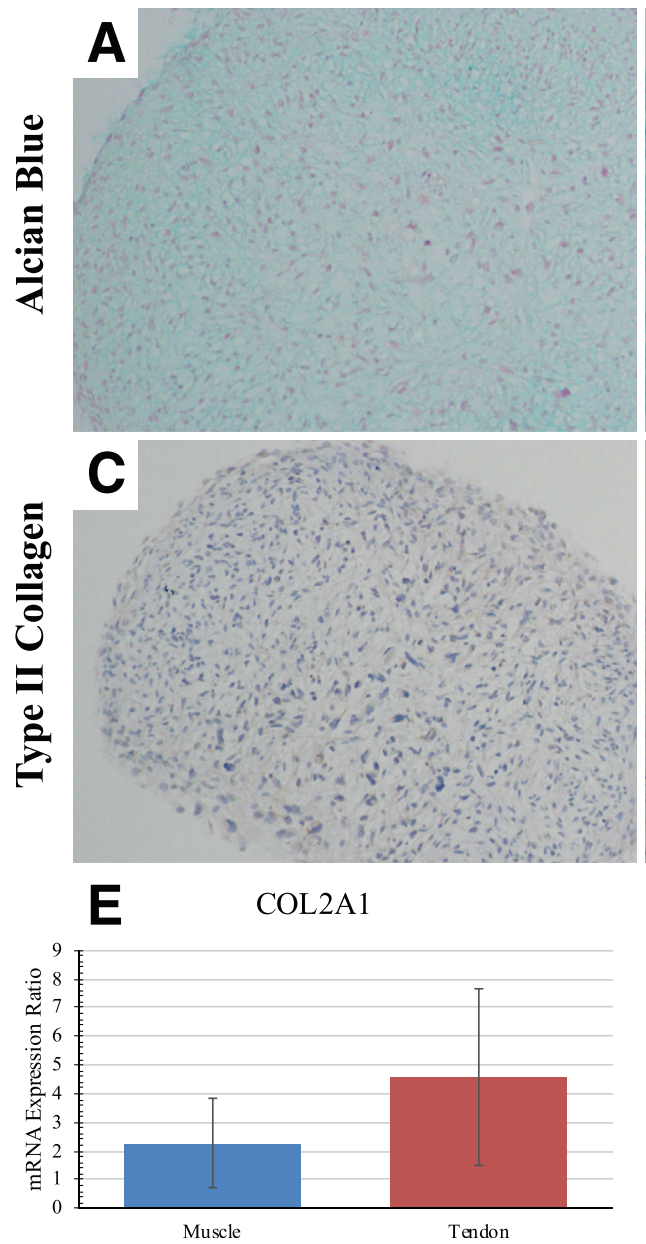
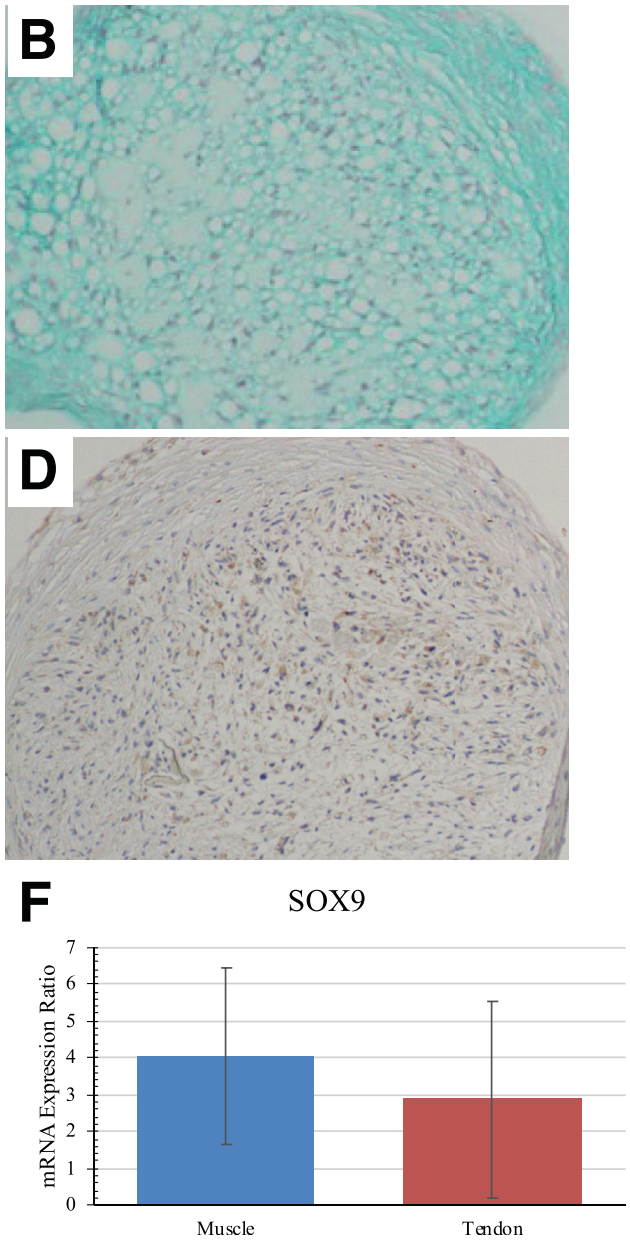

Fig 7. Chondrogenic differentiation immunostaining and quantitative PCR. Alcian Blue and type II collagen staining in controls (A and $\mathrm{C}$, respectively) and those induced with chondrogenic differentiation media (B and D, respectively) at $\times 10$ magnification. Trochanteric bursa overlying the gluteus medius muscle and tendon revealed similar gene expression ratios for both COL2Al (E) $(P=.463)$ and SOX9 (F) $(P=.600)$. COL2Al, collagen type II $\alpha$; PCR, polymerase chain reaction; SOX9, seX-determining region Y-box 9. the harvested bursa tissue overlying the gluteus medius muscle contained more adipose tissue, which likely explains this difference. This macroscopic observation was similar to those described for the subacromial bursa overlying the rotator cuff. ${ }^{2}$ Like those seen in the current study, other studies investigating bursal tissue have identified greater than $90 \%$ positivity for the CTPspecific surface markers CD73, CD90, and CD105 and negligible rates of the hematopoietic markers CD31 and CD45 using flow cytometry., ${ }^{43,24}$ Moreover, other studies have positively stained osteogenic cells with Alizarin Red, adipogenic cells with Oil Red-O, and chondrogenic cells with Alcian and/or Toluidine Blue. ${ }^{2,13}$

In the shoulder, the subacromial bursa has recently gained attention as a local biologic augment for rotator cuff repairs. ${ }^{2,7,11}$ Studies have identified bursal tissue as an abundant source of progenitor cells, in agreement with the established criterion for mesenchymal stem cells, ${ }^{15}$ as well as manifesting features of hypertrophy, hyperplasia, and neoangiogenesis, further suggesting a role in the reparative response. ${ }^{8,9}$ However, its precise biologic mechanism is unknown.

Importantly, bursal tissue and its role in the healing response of entheses has been limited to the subacromial space and the rotator cuff. The hip abductors, also known as the rotator cuff of the hip, may benefit from local biologic augmentation to enhance healing, durability of repairs, and prevention of further degeneration. The authors recommend cautious removal of bursal tissue during open hip procedures to enhance the reparative response of an individual's native biology.

\section{Limitations}

There are several limitations for this study. First, this is an in vitro study, and these results may not emulate in vivo characteristics or properties. Second, as the determination of mesenchymal stem cells is based on criteria set forth by a consensus, and there is no specific marker used for their identification, ${ }^{1,5}$ the experiments used in this study are used to enhance the probability 
that the identified cells were, in fact, connective tissue progenitor cells. Third, the preoperative integrity of the hip abductor bursa was not assessed for fatty infiltration and muscular atrophy using magnetic resonance imaging, which may contribute to the results identified in this study. Fourth, the small sample size did not provide us the opportunity to stratify data based on demographics to see how factors such as age, gender, previous intra-articular corticosteroid injections, alcohol use, and smoking status may contribute to the results identified in the study.

\section{Conclusion}

Connective tissue progenitor cells are found in the trochanteric bursa overlying the muscle and tendon of the hip abductors.

\section{References}

1. Utsunomiya H, Uchida S, Sekiya I, Sakai A, Moridera K, Nakamura T. Isolation and characterization of human mesenchymal stem cells derived from shoulder tissues involved in rotator cuff tears. Am J Sports Med 2013;41: 657-668.

2. Morikawa D, Johnson JD, Kia C, et al. Examining the potency of subacromial bursal cells as a potential augmentation for rotator cuff healing: An in vitro study. Arthroscopy 2019;35:2978-2988.

3. Muench LN, Baldino JB, Berthold DP, et al. Subacromial bursa-derived cells demonstrate high proliferation potential regardless of patient demographics and rotator cuff tear characteristics. Arthroscopy 2020;36:2794-2802.

4. Morikawa D, Muench LN, Baldino JB, et al. Comparison of preparation techniques for isolating subacromial bursaderived cells as a potential augment for rotator cuff repair. Arthroscopy 2020;36:80-85.

5. Gulotta LV, Kovacevic D, Packer JD, Deng XH, Rodeo SA. Bone marrow-derived mesenchymal stem cells transduced with scleraxis improve rotator cuff healing in a rat model. Am J Sports Med 201 1;39:1282-1289.

6. Song N, Armstrong AD, Li F, Ouyang H, Niyibizi C. Multipotent mesenchymal stem cells from human subacromial bursa: Potential for cell-based tendon tissue engineering. Tissue Eng Part A 2014;20:239-249.

7. Muench LN, Kia C, Berthold DP, et al. Preliminary clinical outcomes following biologic augmentation of arthroscopic rotator cuff repair using subacromial bursa, concentrated bone marrow aspirate, and platelet-rich plasma. Arthrosc Sport Med Rehabil 2020;2:e803-e813.

8. Chillemi C, Petrozza V, Garro L, et al. Rotator cuff re-tear or non-healing: Histopathological aspects and predictive factors. Knee Surg Sport Traumatol Arthrosc 201 1;19:1588-1596.

9. Chillemi C, Petrozza V, Franceschini V, et al. The role of tendon and subacromial bursa in rotator cuff tear pain: A clinical and histopathological study. Knee Surg Sport Traumatol Arthrosc 2016;24:3779-3786.

10. Uhthoff H, Sarkar K. Surgical repair of rotator cuff ruptures: The importance of the subacromial bursa. Bone Jt Surg $\mathrm{Br} 1991 ; 73: 399-401$.
11. Dyrna F, Zakko P, Pauzenberger L, McCarthy MB, Mazzocca AD, Dyment NA. Human subacromial bursal cells display superior engraftment versus bone marrow stromal cells in murine tendon repair. Am J Sports Med 2018;46:3511-3520.

12. Dyment NA, Liu CF, Kazemi N, et al. The paratenon contributes to scleraxis-expressing cells during patellar tendon healing. PLoS One 2013;8:1-11.

13. Steinert AF, Kunz M, Prager P, et al. Characterization of bursa subacromialis-derived mesenchymal stem cells. Stem Cell Res Ther 2015;6:1-14.

14. Ahn HJ, Lee WJ, Kwack KB, Kwon Y Do. FGF2 stimulates the proliferation of human mesenchymal stem cells through the transient activation of JNK signaling. FEBS Lett 2009;583:2922-2926.

15. Dominici M, Le Blanc K, Mueller I, et al. Minimal criteria for defining multipotent mesenchymal stromal cells. The International Society for Cellular Therapy position statement. Cytotherapy 2006;8:315-317.

16. Yang Z, Schmitt J, Lee E. Immunohistochemical analysis of human mesenchymal stem cells differentiating into chondrogenic, osteogenic, and adipogenic lineages, Methods Mol Biol 2011;698:353-366.

17. Futami I, Ishijima M, Kaneko H, et al. Isolation and characterization of multipotential mesenchymal cells from the mouse synovium. PLoS One 2012;7:1-12.

18. Nazal MR, McCarthy MBR, Mazzocca AD, Martin SD. Connective tissue progenitor analysis of bone marrow aspirate concentrate harvested from the body of the ilium during arthroscopic acetabular labral repair. Arthroscopy 2020;36:1311-1320.

19. Manolagas S, Jilka R. Bone marrow, cytokines, and bone remodeling. Emerging insights into the pathophysiology of osteoporosis. N Engl J Med 1995;332:305-311.

20. Katagiri K, Matsukura Y, Muneta T, et al. Fibrous synovium releases higher numbers of mesenchymal stem cells than adipose synovium in a suspended synovium culture model. Arthroscopy 2017;33:800-810.

21. Hatakeyama A, Uchida S, Utsunomiya H, et al. Isolation and characterization of synovial mesenchymal stem cellderived from hip joints: A comparative analysis with a matched control knee group. Stem Cells Int 2017;2017: $1-13$.

22. Yi SW, Kim HJ, Oh HJ, et al. Gene expression profiling of chondrogenic differentiation by dexamethasoneconjugated polyethyleneimine with SOX trio genes in stem cells. Stem Cell Res Ther 2018;9:1-13.

23. Baldino JB, Muench LN, Kia C, et al. Intraoperative and in vitro classification of subacromial bursal tissue. Arthroscopy 2020;36:2057-2068.

24. Landry A, Levy BJ, McCarthy MB, et al. Analysis of time to form colony units for connective tissue progenitor cells (stem cells) harvested from concentrated bone marrow aspirate and subacromial bursa tissue in patients undergoing rotator cuff repair. Arthrosc Sport Med Rehabil 2020;2: e629-e636.

25. Kagan AI. Rotator cuff tears of the hip. Clin Orthop Relat Res 1999;368:135-140.

26. Bunker T, Esler C, Leach W. Rotator-cuff tear of the hip. J Bone Jt Surg Br 1997;79:618-620. 
27. Howell G, Biggs R, Bourne R. Prevalence of abductor mechanism tears of the hips in patients with osteoarthritis. J Arthroplast 2001;16:121-123.

28. Hendry J, Biant L, Breusch S. Abductor mechanism tears in primary total hip arthroplasty. Arch Orthop Trauma Surg 2012;132:1619-1623.
29. Miozzari H, Dora C, Clark J, Nötzli H. Late repair of abductor avulsion after the transgluteal approach for hip arthroplasty. J Arthroplast 2010;25:450-457.

30. Dyrna F, Herbst E, Hoberman A, Imhoff AB, Schmitt A. Stem cell procedures in arthroscopic surgery. Eur J Med Res 2016;21:29-36. 